\title{
Effects of Ramadan Fasting on Biochemical and Anthropometric Parameters in Physically Active Men
}

\author{
Khaled Trabelsi*1, MS; Kais el Abed ${ }^{2}$, MS; John F. Trepanowski ${ }^{3}$, MS; Stephen R. Stannard ${ }^{4}$, PhD; Zohra Ghlissi ${ }^{1}$, MS; \\ Hanene Ghozzi ${ }^{1}$, PhD; Liwa Masmoudi ${ }^{1}$, MS; Kamel Jammoussi ${ }^{5}$, PhD; Ahmed Hakim ${ }^{1}$, PhD
}

Authors' Affiliation:

1. Laboratory of Pharmacology, Faculty of Medicine, University of Sfax, Tunisia

2. Laboratory of Cardio-Circulatory, Respiratory, Metabolic and Hormonal Adaptations to the Muscular Exercise, Faculty of Medicine Ibn El Jazzar, Tunisia

3. Cardiorespiratory/Metabolic Laboratory, University of Memphis, Memphis, USA

4. Institute of Food, Nutrition and Human Health, Massey University, New Zealand

5. Department of Biochemistry of the Hedi Chaker University Hospital, Tunisia

* Corresponding Author;

Address: Laboratoire de Pharmacologie, faculté de médecine de Sfax, avenue Majda Boulila, 3029 Sfax, Tunisie

E-mail: trabelsikhaled@gmail.com

Received: Feb 07, 2011

Accepted: May 20, 2011

Key Words: Islamic Fasting; Aerobic Exercise; Dehydration; Body Composition; Lipids Profile

\section{Abstract}

Purpose: The aim of this study was to assess the effects of Ramadan fasting on several biochemical and anthropometric parameters in physically active men by comparing fasters and nonfasters before, during, and after Ramadan.

Methods: Eighteen physically active men (10 fasters and 8 nonfasters) participated in this study. Subjects visited the laboratory for a total of four sessions on the following occasions: three days before Ramadan (Bef-R), the $15^{\text {th }}$ day of Ramadan (Mid-R), the $29^{\text {th }}$ day of Ramadan (End-R), and 21 days after Ramadan (Post-R). During each session, subjects underwent anthropometric measurements, completed a dietary questionnaire and provided a fasting blood sample.

Results: Body weight and body fat percentage decreased in fasters by $1.9 \%$ $(P<0.001)$ and $6.2 \%(P=0.003)$, respectively, but increased in nonfasters by $2.2 \%(P<0.001)$ and $10.2 \%(P=0.001)$, respectively, from Bef-R to End-R. Fasters' hematocrit and hemoglobin increased by $5.3 \%(P<0.001)$ and $6.3 \%(P=0.01)$, respectively, from Bef-R to End-R, while neither of these parameters changed in nonfasters. Fasters experienced an increase in the following parameters from Bef-R to End-R: urea $(8.7 \% ; P<0.001)$, creatinine $(7.5 \% ; P<0.001)$, uric acid $(12.7 \% ; P<0.001)$, serum sodium $(1.9 \% ; P<0.001)$, serum chloride $(2.6 \% ; P<0.001)$ and high-density lipoprotein cholesterol $(27.3 \% ; P<0.001)$. Of these parameters, only creatinine increased $(4.4 \% ; P=0.01)$ in nonfasters.

Conclusions: We conclude that Ramadan fasting lowers body weight and body fat percentage and can elevate high-density lipoprotein cholesterol in physically active men. However, practicing aerobic exercise during a hot and humid Ramadan month can induce a state of dehydration marked by an increase in some renal function markers and serum electrolytes.

Asian Journal of Sports Medicine, Volume 2 (Number 3), September 2011, Pages: 134-144

\section{INTRODUCTION}

$\mathrm{R}$ amadan fasting, one of the five pillars of Islam, occurs during the $9^{\text {th }}$ lunar month of the Islamic calendar. During this holy month, Muslims are allowed to eat and drink only between sunset and dawn. A comprehensive review of Ramadan fasting has recently been published ${ }^{[1]}$, but the basic information regarding changes in dietary intake and body composition are as follows: The majority of Muslims typically consume 
two meals per day during this month: one immediately after sunset and the other just before dawn ${ }^{[2]}$. Thus, both the frequency ${ }^{[3,4]}$ and quantity ${ }^{[5]}$ of food intake are usually reduced during Ramadan. As would be expected, caloric intake is often reduced during this month ${ }^{[6]}$, which results in reduced body weight ${ }^{[6,7,8,9]}$. However, some investigations have reported no significant changes in body weight or body composition during Ramadan ${ }^{[10,11,12]}$.

The few investigations that have examined the effects of Ramadan fasting on hematological parameters in physically active Muslims have reported mostly heterogeneous findings. In fact, hematocrit and hemoglobin have both been reported to increase ${ }^{[6]}$, decrease ${ }^{[12]}$, and not change ${ }^{[9]}$ during Ramadan.

Ramadan fasting has been demonstrated to modify the lipid profile of athletes. Total cholesterol, highdensity (HDL-C) and low-density lipoprotein cholesterol have each been shown to increase in elite judokas ${ }^{[7]}$. Also, free fatty acid levels have been shown to increase in middle-distance runners ${ }^{[10]}$. Due to the fact that blood lipids can substantially change during Ramadan, fasters should have their lipid profiles regularly monitored.

During Ramadan, a decrease in serum glucose has been noted in runners ${ }^{[13]}$ and moderately-trained men ${ }^{[14]}$, while an absence of change has been observed in soccer players ${ }^{[12]}$ and elite rugby players ${ }^{[6]}$.

Several markers of renal function have been studied during Ramadan. Maughan et al ${ }^{[12]}$ reported an increase in creatinine concentrations and a decrease in urea concentrations. However, another investigation ${ }^{[8]}$ noted no change in either parameter. Uric acid has been reported to increase in elite judokas ${ }^{[7]}$ but not change in soccer players ${ }^{[12]}$ or physically active men ${ }^{[8]}$.

Several studies have examined the combined effects of physical activity and Ramadan fasting on serum electrolytes. Maughan et al ${ }^{[12]}$ noted an increase in serum potassium concentrations and no change in serum sodium concentrations in soccer players. Ramadan et al ${ }^{[8]}$ reported an increase in serum bicarbonate and sodium concentrations in sedentary men but no change in either concentration in physically active men.

During Ramadan, some Muslims remain physically active for recreational purposes. However, if the
Ramadan month falls in summer, practicing physical activity during the day places additional stresses on electrolyte balance and possibly also metabolism. In most published studies focusing on the effect of Ramadan fasting on biochemical and anthropometric parameters of physically active men, the environmental conditions during Ramadan have not been described $[9,10,22]$.

To our knowledge, no study has examined the combined effects of exercise and Ramadan fasting on biochemical and anthropometric parameters in physically active Muslims. Therefore, the aim of this study was to assess the effects of Ramadan fasting on several biochemical and anthropometric parameters in physically active men by comparing fasting and nonfasting subjects before, during, and after Ramadan.

\section{METHODS AND SUBJECTS}

\section{Participants:}

Eighteen physically active men (10 fasters and 8 nonfasters) participated in this study. Each of the subjects regularly performed aerobic exercise (i.e., jogging and swimming) for recreational purposes for at least 3 times/week but did not participate in formal competitive sporting activities. Subjects were nonsmokers and did not use/consume drugs or other substances expected to affect the study's parameters. The subjects' descriptive characteristics are provided in Table 1. Prior to enrolling in the study, subjects were informed of the experimental procedures as well as the potential risks and benefits associated with the study; however, subjects were not informed of the study's purpose. To be included in the study, each subject provided written consent in accordance with the Declaration of Helsinki. Subjects were aware that they could withdraw from the study at any time.

\section{Experimental design:}

Ramadan began on August $10^{\text {th }}$ and concluded on September $9^{\text {th }}, 2010$. The study was conducted in Tunisia, where temperatures averaged between 30$35^{\circ} \mathrm{C}$ (approximate values) with an average relative 
Table 1: Descriptive characteristics [mean (standard deviation)] of physically active men

\begin{tabular}{|c|c|c|}
\hline Parameters & Fasters & Nonfasters \\
\hline Age (yrs) & $26.6(3.0)$ & $27.2(3.2)$ \\
\hline Weight (kg) & $79.2(3.0)$ & $78.5(4.3)$ \\
\hline Height (cm) & $180.0(6.4)$ & 173 (3.9)* \\
\hline Body Mass Index $\left(\mathrm{kg} \cdot \mathrm{m}^{-2}\right)$ & $24.6(1.4)$ & $26.3(2.0)$ \\
\hline Body Fat\% & $19.4(1.3)$ & $18.7(2.0)$ \\
\hline Lean Body Mass (kg) & $63.8(3.0)$ & $63.8(3.7)$ \\
\hline Years aerobic training & $1.6(0.7)$ & $1.8(0.2)$ \\
\hline hours/wk aerobic training & $3.0(0.6)$ & $2.8(0.4)$ \\
\hline $\mathrm{VO}_{2} \max \left(\mathrm{ml} \cdot \mathrm{min}^{-1} \cdot \mathrm{Kg}^{-1}\right)$ & $44.6(4.2)$ & $45.3(3.1)$ \\
\hline
\end{tabular}

* Significantly different from fasters: $(P<0.05) / \mathrm{VO}_{2} \max =$ maximal oxygen consumption

humidity of 50-65\% (approximate values). During this period, the daily period of abstinence from food and water experienced by the subjects during Ramadan was approximately 15 h (between 4:00 a.m. and 07:00 p.m.)

Subjects visited the laboratory on four separate occasions: three days before Ramadan (Bef-R), the $15^{\text {th }}$ day of Ramadan (Mid-R), the $29^{\text {th }}$ day of Ramadan (End-R) and 21 days after Ramadan (Post-R). In the morning of each occasion (between 10:00 a.m. and 11:30 a.m.), subjects underwent anthropometric measurements, completed a dietary questionnaire, and provided a fasting blood sample. (See Table 1 for descriptive characteristics). Subjects were instructed not to consume any food or calorie-containing beverage after 11:00 p.m. on the day before Bef-R. During the two weeks before and after the beginning of Ramadan, subjects recorded their exercise sessions along with their rating of perceived exertion (RPE) using the Borg scale ${ }^{[15]}$ (Table 2). During Ramadan, all exercise sessions occurred in the late afternoon (between 4:00 p.m. and 6:00 p.m.). Neither RPE nor the duration of the exercise sessions changed in either fasters or nonfasters during the duration of the study. Additionally, no differences in RPE or the duration of exercise existed between fasters and nonfasters at any time period.

\section{Body composition:}

Subjects' body weight was measured to the nearest 100 g using a calibrated electronic scale, and their height was measured using a stadiometer. Body mass index (BMI) was calculated as weight (kg) divided by height (m) squared. Skinfold thickness was measured using calibrated Harpenden calipers at four standardized sites (biceps, triceps, subscapula and suprailium). Body fat percentage (BF\%) was calculated using the Durnin and Womersley equation ${ }^{[16]}$. Lean body mass (LBM) was calculated as body weight minus body fat mass.

\section{Dietary intake analysis:}

Subjects were instructed to record on data forms all food and beverages consumed during the week before Ramadan. Subjects were also asked to record food and beverage intake three days per week during Ramadan. Dietary records were analyzed using the Bilnut

Table 2: Rating of perceived exertion and duration of training sessions [mean (standard deviation)] before and during Ramadan

\begin{tabular}{|lcccc} 
& \multicolumn{2}{c}{ Before Ramadan } & \multicolumn{2}{c}{ During Ramadan } \\
& Fasters & Non-fasters & Fasters & Nonfasters \\
\hline Rating of perceived exertion & $13.2(1.4)$ & $13.5(1.5)$ & $12.9(1.5)$ & $13.2(2.1)$ \\
Duration of training sessions (min) & $46.5(10.6)$ & $49.4(11.7)$ & $47.5(11.6)$ & $50.3(13.3)$
\end{tabular}


program (Nutrisoft, Cerelles, France) and the food composition tables of the National Institute of Statistics of Tunis (1978). Total water intake was defined as the fluid volume of consumed beverages plus the water content of consumed foods.

\section{Hematological measurements and serum biochemistry:}

During each session, venous blood samples $(\sim 7 \mathrm{ml})$ were taken from subjects' antecubital vein into a plain vacutainer tube. An aliquot of blood was immediately removed and mixed with ethylene diamine tetraacetic acid (EDTA) as an anticoagulant. These blood Samples were analyzed for hemoglobin, hematocrit and blood platelets count using an automated analyzer (Beckman coulter, UK) according to the manufacturer's protocol. The remainder of blood was allowed to clot and then was centrifuged at $1500 \mathrm{~g}$ for $10 \mathrm{~min}$ at $4^{\circ} \mathrm{C}$. An aliquot of the serum was used to measure serum glucose immediately after the centrifugation step; the remainder was then stored at $-20^{\circ} \mathrm{C}$ until subsequent analysis. An automated analyzer (Beckman Coulter Cx9, UK) measured the concentrations of biochemical parameters using the appropriate reactant. Blood glucose, uric acid, total cholesterol and triglycerides were determined using an enzymatic colorimetric method (Biomérieux, France). Urea was determined using an enzymatic method (Biomaghreb, Tunisia). Creatinine concentrations were determined by the Jaffé method. Sodium, potassium and chloride concentrations were determined by potentiometry. High-density lipoprotein cholesterol (HDL-C) concentrations were determined by immuno-inhibition (Elitech, France) using an automated analyzer (Flexor Vitalab, Netherlands).

\section{Statistical analyses}

All statistical tests were performed using STATISTICA Software (StatSoft, Paris, France). A 4 (periods) $\times 2$ (fasting status) repeated-measures analysis of variance (ANOVA) was applied. Fischer LSD post hoc test was performed where appropriate. Differences between fasters and nonfasters were analyzed using non-paired Student's t-test. Statistical significance was set at $P<0.05$. All data are expressed

\section{RESULTS}

Dietary intake: (Table 3)

Estimated mean daily energy intake before Ramadan was similar between fasters and nonfasters. Daily energy intake during Ramadan increased in nonfasters by $11.2 \%(P=0.03)$ but did not change in fasters. Consequently, fasters consumed less energy than nonfasters $(P=0.02)$ during Ramadan.

Protein and fat consumption increased by $18.1 \%$ $(P=0.04)$ and $15.7 \% \quad(P=0.03)$, respectively, in nonfasters during Ramadan; consumption of these macronutrients did not change in fasters during this

Table 3: Dietary intake [mean (standard deviation)] of participants before and during Ramadan

\begin{tabular}{|c|c|c|c|c|}
\hline \multirow{2}{*}{ Parameter } & \multicolumn{2}{|c|}{ Before Ramadan } & \multicolumn{2}{|c|}{ During Ramadan } \\
\hline & Fasters & Nonfasters & Fasters & Nonfasters \\
\hline Energy intake $\left(\mathrm{kcal}^{\left.-\mathrm{d}^{-1}\right)}\right.$ & $2803(511)$ & $2675(356)$ & $2596(311)$ & $2976(342) * \#$ \\
\hline Proteins $\left(g \cdot d^{-1}-^{1}\right)$ & $90.6(18.4)$ & $85.6 \pm 17.14)$ & $96.6(13.0)$ & $101.1(11.1)^{*}$ \\
\hline Proteins (\%) & $13.2(2.8)$ & $12.9(2.3)$ & $15.1(2.5)^{* *}$ & $13.7(2.1)$ \\
\hline Fats $\left(g \cdot d^{-1}\right)$ & $102.9(27.4)$ & $104.1(24.8)$ & $95.1(15.3)$ & $120.5(12.2)^{* \#}$ \\
\hline Fats $(\%)$ & $33.1(6.0)$ & $35.4(8.8)$ & $33.0(3.4)$ & $36.8(5.0)$ \\
\hline Carbohydrates $\left(g \cdot d^{-1}\right)$ & $378.5(93.7)$ & $344.3(67.6)$ & $359.8(55.5)^{*}$ & $338.3(56.0)$ \\
\hline Carbohydrates (\%) & $53.7(6.2)$ & $51.6(6.6)$ & $52(3.4)$ & $49.5(6.1)$ \\
\hline Total water intake $\left(L \cdot d^{-1}\right)$ & $4.0(0.5)$ & $4.2(0.4)$ & $3.3(0.3)^{* *}$ & $3.9(0.5) \#$ \\
\hline
\end{tabular}

Significantly different from before Ramadan: * $(P<0.05)$; ** $(P<0.01)$. Significantly different from fasters: \#(P<0.05) 
month. Carbohydrate consumption decreased by $4.9 \%$ $(P=0.02)$ in fasters but did not change in nonfasters.

Expressed as a percentage of daily macronutrient intake, protein intake increased by $14 \%(P=0.006)$ in fasters but did not change in nonfasters during Ramadan. Both fat intake and carbohydrate intake (expressed as a percentage of daily macronutrient intake) did not change during Ramadan in either fasters or nonfasters. Before Ramadan, intake of protein, fat and carbohydrates was similar between fasters and nonfasters. During Ramadan, fasters consumed less fat (expressed as an absolute amount) than nonfasters $(P=0.001)$. Total water intake decreased by $17.5 \%$ $(P=0.009)$ in fasters but did not change in nonfasters.

\section{Body weight and body composition: (Table 4, 5)}

The two-way ANOVA (periods $\times$ fasting status) for body weight showed no significant effects for periods $\left(\mathrm{F}_{(3,48)}=0.8 ; P=0.5\right)$ or for fasting status $\left(\mathrm{F}_{(1,16)}=0.2\right.$; $P=0.6)$. However, there was a significant periods $\times$ fasting status interaction $\left(\mathrm{F}_{(3,48)}=19.1 ; P<0.001\right)$. The post hoc test revealed that compared to values at Bef$\mathrm{R}$, fasters' body weight was $1.4 \%$ less at Mid-R $(P<0.001)$ and $1.9 \%$ less at End-R $(P<0.001)$. Nonfasters body weight was $1 \%$ greater at Mid-R $(P=0.01)$, 2.2\% greater $(P<0.001)$ at End-R and $1 \%$ greater at Post-R $(P=0.01)$ compared to Bef-R. There was no difference in body weight between fasters and nonfasters at any time period in the study.

There was no significant effect for periods $\left(\mathrm{F}_{(3,48)}=\right.$ 1.8; $P=0.1$ ), no significant effect for fasting status $\left(\mathrm{F}_{(1,16)}=7.0 ; P=0.02\right)$ and a significant effect for periods $\times$ fasting status interaction $\left(\mathrm{F}_{(3,48)}=16.6 ; P<0.001\right)$ on BMI. The post hoc test revealed that compared to values at Bef-R, fasters' BMI was $0.8 \%$ less at Mid-R $(P=0.004)$ and $2.8 \%$ less at End-R $(P<0.001)$. Nonfasters' BMI was $1.1 \%$ greater at End-R $(P<0.001)$ compared to Bef-R. There was no difference in BMI between fasters and nonfasters at any time period in the study.

The two-way ANOVA (periods $\times$ fasting status) for $\mathrm{BF} \%$ showed no significant effects for periods $\left(F_{(3,48)}=0.7 ; P=0.6\right)$ or for fasting status $\left(F_{(1,16)}=2.9\right.$; $P=0.1)$. However, there was a significant periods $\times$ fasting status interaction $\left(\mathrm{F}_{(3,48)}=10.6 ; P<0.001\right)$. The post hoc test showed that compared to values at Bef-R, fasters' BF\% decreased by $4.1 \%$ at Mid-R $(P=0.04)$ and by $6.2 \%$ at End-R $(P=0.003)$. Nonfasters' BF\% was $7.5 \%$ higher at Mid-R $(P=0.001)$ and $10.2 \%$ higher at End-R $(P=0.001)$ compared to Bef-R. Nonfasters' $\mathrm{BF} \%$ was greater than fasters' $\mathrm{BF} \%$ at End-R $(P=0.046)$.

There was no significant effect for periods $\left(\mathrm{F}_{(3,48)}=0.7 ; P=0.6\right)$; no significant effect for fasting status $\left(\mathrm{F}_{(1,16)}=0.001 ; P=1\right)$ or the interaction between the two $\left(\mathrm{F}_{(3,48)}=0.1 ; P=0.9\right)$ on the LBM. There was no significant main effect of periods $(P=0.8)$ on fasters and nonfasters $(P=0.6)$ LBM. There was no difference in LBM between fasters and nonfasters at any time period in the study.

\section{Hematological and biochemical parameters: (Table 6, 7)}

The two-way ANOVA (periods $\times$ fasting status) for hematocrit showed a significant effect for periods

Table 4: Body weight and body composition [mean (standard deviation)] during the four phases of the study

\begin{tabular}{llcccc} 
Parameter & Group & Before Ramadan & Middle of Ramadan & End of Ramadan & After Ramadan \\
Weight (kg) & Fasters & $79.2 \pm 3$ & $78.1 \pm 3^{* * *}$ & $77.7 \pm 3^{* * *}$ & $78.7 \pm 2.7$ \\
& Nonfasters & $78.5 \pm 4.3$ & $79.3 \pm 4.7^{*}$ & $80.2 \pm 5.1^{* * *}$ & $79.3 \pm 4.9 *$ \\
Body Mass Index & Fasters & $24.8 \pm 1.6$ & $24.3 \pm 1.5^{* *}$ & $24.1 \pm 1.6^{* * *}$ & $24.5 \pm 1.6$ \\
$\mathbf{( k g \cdot \mathbf { m } ^ { - 2 } )}$ & Nonfasters & $26.6 \pm 2.2$ & $26.6 \pm 2.2$ & $26.9 \pm 2.2^{* * *}$ & $26.6 \pm 2.2$ \\
& Fody Fat\% & $19.4 \pm 1.3$ & $18.6 \pm 1.5^{*}$ & $18.2 \pm 0.7 * *$ & $18.9 \pm 1.5$ \\
Lean Body Mass & Nonfasters & $18.7 \pm 2$ & $20.1 \pm 1.4^{* *}$ & $20.6 \pm 1.1^{* * * \#}$ & $19.5 \pm 1.4$ \\
$(\mathbf{k g})$ & Fasters & $63.8 \pm 3$ & $63.6 \pm 2.7$ & $63.6 \pm 2.7$ & $63.9 \pm 3.1$ \\
\hline
\end{tabular}

Significantly different from before Ramadan: * $(P<0.05)$; ** $(P<0.01)$; *** $(P<0.001)$. Significantly different from fasters: \# $(P<0.05)$. Before Ramadan: 4 days before beginning the fast; Middle of Ramadan: 15 days after beginning the fast; End of Ramadan: 30 days after beginning the fast; After Ramadan: 21 days after the conclusion of the fast. 
$\left(\mathrm{F}_{(3,48)}=3.0 ; P=0.04\right)$, no significant effect for fasting status $\left(\mathrm{F}_{(1,16)}=0.5 ; P=0.5\right)$ and a significant effect for periods $\times$ fasting status interaction $\left(\mathrm{F}_{(3,48)}=3.2 ; P=0.03\right)$. The post hoc test revealed that compared to values at Bef-R, fasters' hematocrit was $5.1 \%$ higher at Mid-R $(P<0.001)$ and $5.3 \%$ higher at End-R $(P<0.001)$. However, nonfasters' hematocrit did not change during Ramadan compared to Bef-R. There was no difference in hematocrit values between fasters and nonfasters throughout the study.

The two-way ANOVA (periods $\times$ fasting status) for hemoglobin showed no significant effects for periods $\left(\mathrm{F}_{(3,48)}=3.0 ; P=0.06\right)$ or for fasting status $\left(\mathrm{F}_{(1,16)}=1.7\right.$; $P=0.2)$. However, there was a significant periods $\times$ fasting status interaction $\left(\mathrm{F}_{(3,48)}=2.9 ; P=0.04\right)$. The post hoc test revealed that compared to values at Bef-R, hemoglobin values were $6.3 \%$ higher at both Mid-R $(P<0.001)$ and End-R $(P<0.001)$. However, nonfasters' hemoglobin values did not change during Ramadan compared to Bef-R. No differences existed in hemoglobin values between fasters and nonfasters throughout the study.

There was no significant effect for periods $\left(\mathrm{F}_{(3,48)}=1.2 ; P=0.3\right)$; no significant effect for fasting status $\left(\mathrm{F}_{(1,16)}=1.2 ; P=0.3\right)$ or the interaction between the two $\left(\mathrm{F}_{(3,48)}=1.3 ; P=0.3\right)$ on the blood platelets. There was no significant main effect of periods on fasters $(P=0.8)$ and nonfasters $(P=0.7)$ blood platelets. No differences existed in blood platelets between fasters and nonfasters at any time period in the study.

The two-way ANOVA (periods $\times$ fasting status) for urea showed a significant effects for periods $\left(F_{(3,48)}=3.1 ; P=0.04\right)$, no significant effect for fasting status $\left(F_{(1,16)}=0.04 ; P=0.8\right)$ or the interaction between the two $\left(\mathrm{F}_{(3,48)}=1.4 ; P=0.2\right)$. There was a significant main effect of periods $(P<0.001)$ on fasters' urea values. The post hoc test revealed that compared to values at Bef-R, fasters' urea were 8.7\% higher at End$\mathrm{R}(P<0.001)$. There was no significant main effect of periods $(P=0.8)$ on nonfasters' urea values.

There was a significant effect of periods $\left(F_{(3,48)}=19.1 ; P<0.001\right)$, no significant effect for fasting status $\left(\mathrm{F}_{(1,16)}=0.04 ; P=0.8\right)$ and a significant effect for periods $\times$ fasting status interaction $\left(\mathrm{F}_{(3,48)}=3.0 ; P=0.04\right)$ on creatinine values. The post hoc test revealed that compared to values at Bef-R, fasters' creatinine values increased by $3.2 \%$ at Mid-R $(P=0.04)$ and by $7.5 \%$ at End-R $(P<0.001)$. However, nonfasters' creatinine values increased by $4.4 \%$ from Bef-R to End-R $(P=0.01)$.

The two-way ANOVA (periods $\times$ fasting status) for uric acid showed a significant effect for periods $\left(F_{(3,48)}=5.8 ; P=0.002\right)$, no significant effect for fasting status $\left(F_{(1,16)}=1.3 ; P=0.3\right)$ and a significant effect of periods $\times$ fasting status interaction $\left(\mathrm{F}_{(3,48)}=4.8\right.$; $P=0.005)$. The post hoc test revealed that compared to values at Bef-R, fasters' uric acid values were $10.4 \%$ larger at Mid-R $(P<0.001)$ and $12.7 \%$ larger at End-R $(P<0.001)$. Nonfasters' uric acid values did not change throughout the study. No differences existed in urea, creatinine and uric acid values between fasters and nonfasters throughout the study.

Table 5: 95\% confidence interval of change of body weight and body composition during the four phases of the study

\begin{tabular}{|c|c|c|c|c|}
\hline Parameters & Group & Bef-R vs Mid-R & Bef-R vs End-R & Bef-R vs Post-R \\
\hline \multirow{2}{*}{ Body weight (Kg) } & Fasters & (77.3 to 80 ) & (77.1 to 79.8 ) & (77.7 to 80.2 ) \\
\hline & Nonfasters & (76.8 to 81 ) & (77.1 to 81.6 ) & (76.7 to 81.1 ) \\
\hline \multirow{2}{*}{$\begin{array}{l}\text { Body Mass Index } \\
(\text { Kg・M-2) }\end{array}$} & Fasters & (14.6 to 15.3 ) & (14.5 to 15.4$)$ & (14.4 to 15.1 ) \\
\hline & Nonfasters & (14.3 to 15.1 ) & (14.1 to 15$)$ & (14.3 to 14.9$)$ \\
\hline \multirow{2}{*}{ Body Fat \% } & Fasters & (18.4 to 19.6 ) & (18.3 to 19.3 ) & (18.6 to 19.8 ) \\
\hline & Nonfasters & (18.5 to 20.3 ) & (18.7 to 20.5 ) & (18.3 to 19.9 ) \\
\hline \multirow{2}{*}{$\begin{array}{l}\text { Lean Body Mass } \\
\text { (kg) }\end{array}$} & Fasters & (62.5 to 64.9) & (62.5 to 64.9$)$ & (62.6 to 65.2) \\
\hline & Nonfasters & (61.8 to 65.4$)$ & (61.9 to 65.6$)$ & (61.9 to 65.9 ) \\
\hline
\end{tabular}

Before Ramadan (Bef-R): 4 days before beginning the fast; middle of Ramadan (Mid-R): 15 days after beginning the fast; end of Ramadan (End-R): 30 days after beginning the fast; after Ramadan (Post-R): 21 days after the conclusion of the fast. 
Table 6: Hematological and biochemical parameters [mean (SD)] during the four phases of the study

\begin{tabular}{|c|c|c|c|c|c|}
\hline Parameters & Group & Before Ramadan & Middle of Ramadan & End of Ramadan & After Ramadan \\
\hline \multirow{2}{*}{ Hematocrit (\%) } & Fasters & $43.6(2.5)$ & $45.9(2.0) * * *$ & $45.9(1.3)^{* * *}$ & $44.2(1.2)$ \\
\hline & Nonfasters & $44.3(2.3)$ & 44.5 (2.9) & $44.1(2.0)$ & $44.3(1.8)$ \\
\hline \multirow{2}{*}{ Hemoglobin $\left(g \cdot \mathrm{dl}^{-1}\right)$} & Fasters & $14.4(0.9)$ & $15.3(0.6) * *$ & $15.3(0.9)^{* *}$ & $15(0.6)$ \\
\hline & Nonfasters & $14.6(0.8)$ & $14.8(0.8)$ & $14.4(1.0)$ & $14.6(0.6)$ \\
\hline \multirow{2}{*}{ Blood platelets $\left(10^{3} \cdot \mu \mathrm{L}^{-1}\right)$} & Fasters & $256.3(37.1)$ & $251.6(39.3)$ & $252.6(34.7)$ & 254 (38.5) \\
\hline & Nonfasters & 246.9 (38.1) & 244.6 (33.4) & 244.7 (37.3) & 244.2 (31.9) \\
\hline \multirow{2}{*}{ Urea $\left(\mathrm{mmol} \cdot \mathrm{l}^{-1}\right)$} & Fasters & $4.6(0.4)$ & $4.7(0.5)$ & $5(0.3)^{* * *}$ & $4.5(0.4)$ \\
\hline & Nonfasters & $4.6(0.3)$ & $4.7(0.5)$ & $4.7(0.6)$ & $4.6(0.5)$ \\
\hline \multirow{2}{*}{ Creatinine $\left(\mu \mathrm{mol} \cdot \mathrm{l}^{-1}\right)$} & Fasters & $87.8(5.9)$ & $90.6(3.2)^{*}$ & $94.4(4.0)^{* * *}$ & $85.8(4.8)$ \\
\hline & Nonfasters & $89.5(4.2)$ & $87.2(3)$ & $93.4(2.3)^{*}$ & $87.5(2.2)$ \\
\hline \multirow{2}{*}{ Uric acid $\left(\mu \mathrm{mol} \cdot \mathrm{l}^{-1}\right)$} & Fasters & $298.5(53.0)$ & $329.5(47.2)^{*}$ & $336.5(39.5)^{* *}$ & $302.1(40.4)$ \\
\hline & Nonfasters & $291(49.4)$ & $295.9(48.3$ & 294.1 (34.1)\# & 295.9 (37.8) \\
\hline \multirow{2}{*}{ Sodium $\left(\mathbf{m m o l} \cdot \mathrm{l}^{-1}\right)$} & Fasters & $142.1(2.1)$ & $144.5(2.5)^{* *}$ & $144.8(1.8)^{* * *}$ & $142.9(1.0)$ \\
\hline & Nonfasters & $141.7(1.5)$ & 142.4 (1.8)\# & 142.2 (1.4)\#\# & $142(0.8)$ \\
\hline \multirow{2}{*}{ Potassium $\left(\mathrm{mmol} \cdot \mathrm{l}^{-1}\right)$} & Fasters & $4.4(0.4)$ & $4.4(0.3)$ & $4.4(0.3)$ & $4.4(0.3)$ \\
\hline & Nonfasters & $4.4(0.3)$ & $4.3(0.4)$ & $4.4(0.5)$ & $4.4(0.3)$ \\
\hline \multirow{2}{*}{ Chloride $\left(\mathrm{mmol} \cdot \mathrm{l}^{-1}\right)$} & Fasters & $102.7(1.6)$ & $103(1.3)$ & $105.4(1.3)^{* * *}$ & $103.1(1.8)$ \\
\hline & Nonfasters & $103.5(1.4)$ & $102.5(0.9)$ & 102.6 (1.1)\# & $103.6(2.3)$ \\
\hline \multirow{2}{*}{ Triglycerides $\left(\mathrm{mmol} \cdot \mathrm{l}^{-1}\right)$} & Fasters & $0.7(0.2)$ & $0.8(0.2)$ & $0.8(0.1)$ & $0.7(0.1)$ \\
\hline & Nonfasters & $0.7(0.2)$ & $0.7(0.1)$ & $0.7(0.1)$ & $0.7(0.1)$ \\
\hline \multirow{2}{*}{$\mathrm{TC}\left(\mathrm{mmol} \cdot \mathrm{l}^{-1}\right)$} & Fasters & $3.9(0.4)$ & $4.1(0.3)$ & $4.1(0.3)$ & $3.9(0.3)$ \\
\hline & Nonfasters & $3.9(0.5)$ & $3.8(0.4)$ & $3.8(0.4)$ & $3.8(0.3)$ \\
\hline \multirow{2}{*}{ HDL-C (mmol· $\left.{ }^{-1}\right)$} & Fasters & $1.1(0.2)$ & $1.3(0.2)^{*}$ & $1.4(0.3)^{* * *}$ & $1.3(0.2)^{*}$ \\
\hline & Nonfasters & $1.2(0.2)$ & $1.1(0.2) \#$ & $1.1(0.2)$ & $1.1(0.3)$ \\
\hline \multirow{2}{*}{ Glucose $\left(\mathrm{mmol} \cdot \mathrm{I}^{-1}\right)$} & Fasters & $4.9(0.4)$ & $4.8(0.6)$ & $4.8(0.5)$ & $4.9(0.5)$ \\
\hline & Nonfasters & $4.7(0.5)$ & $4.7(0.4)$ & $4.7(0.4)$ & $4.8(0.5)$ \\
\hline
\end{tabular}

Significantly different from before Ramadan: * $(P<0.05)$; ** $(P<0.01)$; *** $(P<0.001)$. Significantly different from fasters: \# $(P<0.05)$; \#\# ( $P<0.01)$. SD: Standard devition / TC: total cholesterol / HDL-C = high-density lipoprotein cholesterol.

Before Ramadan: 4 days before beginning the fast; Middle of Ramadan: 15 days after beginning the fast; end of Ramadan (End-R): 30 days after beginning the fast; after Ramadan: 21 days after the conclusion of the fast.

The two-way ANOVA (periods $\times$ fasting status) for serum sodium concentrations showed a significant effect for periods $\left(\mathrm{F}_{(3,48)}=5.7 ; P=0.002\right)$, a significant effect for fasting status $\left(\mathrm{F}_{(1,16)}=7.1 ; P=0.02\right)$ and no significant effect for periods $\times$ fasting status interaction $\left(\mathrm{F}_{(3,48)}=2.5 ; P=0.07\right)$. There was a significant main effect of periods $(P<0.001)$ on fasters' sodium concentrations. The post hoc test revealed that compared to values at Bef-R, fasters' serum sodium concentrations were $1.7 \%$ higher at Mid-R $(P=0.001)$ and $1.9 \%$ higher at End-R $(P<0.001)$. However, There was no significant main effect of periods $(p=0.727)$ on nonfasters' sodium values. Fasters' serum sodium concentrations were larger than nonfasters' at Mid-R
$(P=0.04)$ and End-R $(P=0.005)$.

There was no significant effect for periods $\left(\mathrm{F}_{(3,48)}=0.04 ; P=1\right)$; no significant effect for fasting status $\left(\mathrm{F}_{(1,16)}=0.001 ; P=0.9\right)$ or the interaction between the two $\left(F_{(3,48)}=0.2 ; P=0.9\right)$ on serum potassium concentrations. There was no significant main effect of periods on fasters' $(P=0.9)$ and nonfasters' $(P=0.9)$ serum potassium concentrations. Also, no differences in this parameter existed between fasters and nonfasters at any time period of the investigation.

The two-way ANOVA (Periods $\times$ fasting status) for serum chloride showed a significant effect for periods $\left(\mathrm{F}_{(3,48)}=3.3 ; P=0.03\right)$, no significant effect for fasting status $\left(\mathrm{F}_{(1,16)}=0.9 ; P=0.3\right)$ and a significant effect 
Table 7: 95\% confidence interval of change of hematological and biochemical parameters during the four phases of the study

\begin{tabular}{|c|c|c|c|c|}
\hline & & Bef-R vs Mid-R & Bef-R vs End-R & Bef-R vs Post-R \\
\hline \multirow{2}{*}{ Hematocrit (\%) } & Fasters & (43.7 to 45.8$)$ & (43.8 to 45.8 ) & (43 to 44.9 ) \\
\hline & Nonfasters & (43.1 to 45.7 ) & (43.2 to 45.3 ) & (43.3 to 45.3 ) \\
\hline \multirow{2}{*}{ Hemoglobin $\left({\left.\mathrm{g} \bullet \mathrm{dl}^{-1}\right)}^{-1}\right.$} & Fasters & (14.6 to 15.3$)$ & (14.5 to 15.4$)$ & (14.4 to 15.1$)$ \\
\hline & Nonfasters & (14.3 to 15.1$)$ & (14.1 to 15$)$ & (14.3 to 14.9 ) \\
\hline \multirow{2}{*}{ Blood platelets $\left(10^{3} \cdot \mu \mathrm{L}^{-1}\right)$} & Fasters & (237.6 to 270.3 ) & (239.1 to 269.8 ) & (239 to 271.3 ) \\
\hline & Nonfasters & (228.8 to 262.7 ) & (228 to 263.7) & (228.9 to 262.2) \\
\hline \multirow{2}{*}{ Urea $\left(\mathrm{mmol}^{-1}\right)$} & Fasters & (4.7 to 5.1$)$ & (4.7 to 5$)$ & (4.7 to 5.1$)$ \\
\hline & Nonfasters & (4.5 to 4.9$)$ & (4.5 to 4.9$)$ & (4.6 to 5$)$ \\
\hline \multirow{2}{*}{ Creatinine $\left(\mu \mathrm{mol}^{-1} \mathrm{l}^{-1}\right)$} & Fasters & (87.1 to 91.3 ) & (88.5 to 93.7 ) & (84.5 to 89.1 ) \\
\hline & Nonfasters & (86.6 to 90.2 ) & (89.6 to 93.3) & (86.8 to 90.2 ) \\
\hline \multirow{2}{*}{ Uric acid $\left(\mu \mathrm{mol}^{-1} \mathrm{l}^{-1}\right)$} & Fasters & (291.5 to 336.5) & (295.8 to 339.2$)$ & (280.2 to 320.4 ) \\
\hline & Nonfasters & (270.3 to 316.6 ) & (272.5 to 312.7 ) & (272.6 to 314.3) \\
\hline \multirow{2}{*}{ Sodium $\left(\mathrm{mmol}^{-\mathbf{l}^{-1}}\right)$} & Fasters & (142.2 to 144.4$)$ & (142.4 to 144.5$)$ & (141.8 to 143.2 ) \\
\hline & Nonfasters & (141.3 to 142.9 ) & (141.3 to 142.7$)$ & (141.3 to 142.4 ) \\
\hline \multirow{2}{*}{ Potassium $\left(\mathrm{mmol}^{-\mathrm{l}^{-1}}\right)$} & Fasters & (4.2 to 4.5$)$ & (4.3 to 4.6$)$ & (4.2 to 4.5$)$ \\
\hline & Nonfasters & (4.2 to 4.6$)$ & (4.2 to 4.6$)$ & (4.3 to 4.6$)$ \\
\hline \multirow{2}{*}{ Chloride $\left.\left(\mathrm{mmol}^{-1}\right)^{-1}\right)$} & Fasters & (102.2 to 103.5 ) & (103.2 to 104.9 ) & (102.2 to 103.6 ) \\
\hline & Nonfasters & (102.4 to 103.6$)$ & (102.4 to 103.7 ) & (102.7 to 104.5 ) \\
\hline \multirow{2}{*}{ Tryglicerides $\left(\mathrm{mmol}^{-1} \mathbf{l}^{-1}\right)$} & Fasters & (0.7 to 0.8$)$ & (0.7 to 0.8$)$ & (0.6 to 0.8$)$ \\
\hline & Nonfasters & (0.7 to 0.8$)$ & (0.7 to 0.8$)$ & (0.6 to 0.8$)$ \\
\hline \multirow{2}{*}{ Total cholesterol $\left(\mathrm{mmol}^{-1} \mathrm{l}^{-1}\right)$} & Fasters & (3.8 to 4.1 ) & (3.9 to 4.1 ) & (3.8 to 4.1 ) \\
\hline & Nonfasters & (3.6 to 4 ) & (3.6 to 4 ) & (3.6 to 4 ) \\
\hline \multirow{2}{*}{ HDL-C (mmol•l$\left.{ }^{-1}\right)$} & Fasters & (3.8 to 4.1 ) & (3.9 to 4.1 ) & (3.8 to 4.1 ) \\
\hline & Nonfasters & (3.6 to 4) & (3.6 to 4$)$ & (3.6 to 4 ) \\
\hline \multirow{2}{*}{ Glucose $\left(\mathrm{mmol}^{-\bullet^{-1}}\right)$} & Fasters & (4.7 to 5.1 ) & (4.7 to 5 ) & (4.7 to 5.1 ) \\
\hline & Nonfasters & (4.5 to 4.9 ) & (4.5 to 4.9 ) & (4.6 to 5 ) \\
\hline
\end{tabular}

Before Ramadan (Bef-R): 4 days before beginning the fast; Middle of Ramadan (Mid-R): 15 days after beginning the fast; end of Ramadan (End-R): 30 days after beginning the fast; after Ramadan (Post-R): 21 days after the conclusion of the fast.

for periods $\times$ fasting status interaction $\left(\mathrm{F}_{(3,48)}=7.7\right.$; $P<0.001)$. The post hoc test revealed that compared to values at Bef-R, fasters' serum chloride values were $2.6 \%$ larger at End-R $(P<0.001)$. Nonfasters' serum chloride values did not change throughout the study. Fasters' serum chloride values were larger than nonfasters' at End-R $(P=0.01)$.

There was no significant effect for periods $\left(\mathrm{F}_{(3,48)}=1.1 ; P=0.3\right)$; no significant effect for fasting status $\left(\mathrm{F}_{(1,16)}=1.2 ; P=0.3\right)$ or the interaction between the two $\left(\mathrm{F}_{(3,48)}=1.6 ; P=0.2\right)$ on total cholesterol. There was no significant main effect of periods on fasters $(P=0.08)$ and nonfasters $(P=0.8)$ total cholesterol concentrations.
The two-way ANOVA (periods $\times$ fasting status) for triglycerides showed no significant effect for periods $\left(\mathrm{F}_{(3,48)}=1.3 ; P=0.3\right)$; no significant effect for fasting status $\left(\mathrm{F}_{(1,16)}=0.2 ; P=0.7\right)$ or the interaction between the two $\left(\mathrm{F}_{(3,48)}=0.3 ; P=0.8\right)$. There was no significant main effect of periods on fasters $(P=0.4)$ and nonfasters $(P=0.6)$ triglycerides concentrations. Total cholesterol and triglycerides did not change throughout the study in either fasters or nonfasters, and no difference existed between fasters and nonfasters' values throughout the study.

The two-way ANOVA (periods $\times$ fasting status) for HDL-C showed no significant effects for periods $\left(\mathrm{F}_{(3,48)}=1.4 ; P=0.2\right)$ or for fasting status $\left(\mathrm{F}_{(1,16)}=3.0\right.$; 
$P=0.1)$. However, there was a significant periods $\times$ fasting status interaction $\left(\mathrm{F}_{(3,48)}=2.9 ; \quad P=0.047\right)$. Compared to values at Bef-R, fasters' HDL-C was $18.2 \%$ higher at Mid-R ( $P=0.02), 27.3 \%$ higher at End$\mathrm{R}(P<0.001)$, and $27.3 \%$ higher at Post-R $(P=0.01)$. Nonfasters' HDL-C did not change throughout the study and there was no difference between HDL-C values of fasters and nonfasters throughout the study.

The two-way ANOVA (periods $\times$ fasting status) for serum glucose showed no significant effect of periods $\left(\mathrm{F}_{(3,48)}=1.2 ; P=0.3\right)$; no significant effect of fasting status $\left(\mathrm{F}_{(1,16)}=1.2 ; P=0.3\right)$ or the interaction between the two $\left(\mathrm{F}_{(3,48)}=1.3 ; P=0.3\right)$. There was no significant main effect of periods on fasters $(P=0.3)$ and nonfasters $(P=0.4)$ serum glucose concentrations, and no differences existed between the groups at any time period.

\section{DISCUSSION}

Our results show that Ramadan fasting lowers body weight and body fat in physically active men. In addition, Ramadan fasting increases concentrations of urea, uric acid, creatinine, serum levels of sodium and chloride, and HDL-C.

Previous studies have reported that Ramadan fasting decreases body weight and body fat percentage ${ }^{[6,7]}$. It appears that the observed decrease in body weight may be due - at least in part - to dehydration as suggested by Bouhlel et al ${ }^{[6]}$. These decreases may also be partly a function of increased utilization of stored body fat. Such a finding has been reported in previous investigations ${ }^{[8,14]}$. In the present investigation, carbohydrate consumption decreased by $4.9 \%$ during Ramadan, which may have resulted in decreased carbohydrate oxidation and increased fat oxidation. However, due to the fact that we did not measure the respiratory exchange ratio, we cannot know this with certainty.

Fasters' hematocrit and hemoglobin levels increased during Ramadan, which may be due to dehydration. Our findings are in agreement with those of Bouhlel et al ${ }^{[6]}$ and Bigard et al ${ }^{[18]}$, but other investigations have reported opposing findings. Chaouachi et al ${ }^{[7]}$ noted an increase in hematocrit and a decrease in hemoglobin in elite judokas, Maughan et $\mathrm{al}^{[12]}$ noted a decrease in both parameters in soccer players, and Tayebi et al ${ }^{[9]}$ noted no change in either parameter. Differences between studies in exercise regimens, climate, and fluid intake are likely to account for these heterogeneous findings.

Nonfasters' hematocrit and hemoglobin levels did not change during Ramadan, which comes as no surprise given that their total water intake did not change during this month.

Ramadan fasting had no effect on blood platelets. This finding opposes the results of Ramadan et al ${ }^{[8]}$, who attributed a decrease in blood platelets during Ramadan to a deficiency in specific micronutrients (iron and vitamins).

The increases in markers of renal function during Ramadan are most likely caused by dehydration. Moreover, increased urea concentrations may be explained by increased protein breakdown following exercise sessions and/or decreased renal blood flow. Some investigators have also suggested that increased urea concentrations may be caused by exercise-induced energy expenditure and reduced energy intake ${ }^{[19,20]}$.

Creatinine is a waste product of creatine, an important energy storage substance in muscle metabolism ${ }^{[21]}$. In sports medicine, creatinine is used for evaluating the health of athletes, particularly in sporting competitions where hydroelectrolytic balance is critical for success ${ }^{[22]}$. For both fasters and nonfasters in this study, increased serum creatinine levels during Ramadan can possibly be attributed to increased protein consumption. Additionally, dehydration probably led to further elevations of this parameter in the fasting group.

Uric acid, which is the end product of purine metabolism [23] and contributes to $58 \%$ of the antioxidant capacity of plasma on average ${ }^{[24]}$, increased in fasters during Ramadan. Our results are consistent with those of Chaouachi et al ${ }^{[7]}$, who attributed increased uric acid levels to dehydration and increased protein breakdown. Finaud et al ${ }^{[25]}$ reported that serum uric acid increased in judokas who lost $5 \%$ of their body weight via diet and exercise. Taken together, these findings suggest that Ramadan fasting combined with aerobic exercise can improve plasma antioxidant capacity by increasing serum uric acid levels. 
Serum sodium concentration is one indicator of the hydration status of athletes ${ }^{[26]}$. Our findings that serum sodium concentrations increased in response to Ramadan fasting oppose the lack of change reported by other investigations ${ }^{[8,12]}$. The reason for these opposing findings may be due to differences in climate between studies. The average temperature in Tunisia during this study was $30-35^{\circ} \mathrm{C}$, with an average relative humidity of $50-65 \%$. In comparison, the average temperature during the studies conducted by Maughan et al ${ }^{[12]}$ and Ramadan et al. ${ }^{[8]}$ was $26^{\circ} \mathrm{C}$ and $20-25^{\circ} \mathrm{C}$, respectively, with an average relative humidity of $72 \%$ and $25-37^{\circ} \mathrm{C}$, respectively.

Serum chloride concentrations increased during Ramadan, which was likely a consequence of both dehydration and elevations in serum sodium ${ }^{[27]}$.

Ramadan fasting did not affect serum potassium concentrations. The only other investigation (to our knowledge) that examined serum potassium concentrations during Ramadan noted an increase in this parameter in soccer players ${ }^{[12]}$. Due to the dehydration and the elevations in serum sodium and chloride concentrations that occurred in fasting subjects, one might expect that increases in serum potassium concentrations would also be observed. However, a decrease in potassium intake may have offset any effects on serum potassium caused by dehydration.

Despite a decrease in carbohydrate intake during Ramadan, blood glucose did not change, which may be due to an increase in gluconeogenesis. Other investigations have reported a similar lack of effect of Ramadan fasting on blood glucose ${ }^{[6,12]}$.

Fasters' HDL-C increased during Ramadan, a finding that was also observed in a study conducted by Chaouachi et al ${ }^{[7]}$. Increases in HDL-C have been shown to reduce the likelihood of developing atherosclerosis and cardiovascular artery disease ${ }^{[28]}$. However, mechanism(s) by which fasting increases level of HDL-C are not clear, loss of weight in fasters may increase HDL-C. Future studies should include the measurement of other lipoproteins (low-density lipoprotein cholesterol, very low-density lipoprotein cholesterol) and apolipoproteins (apolipoprotein A-1, apolipoprotein A-2) to assess the lipids profile of subjects. An obvious limitation of our study is the small sample size which can make the findings not transferable to overall physically active men.

\section{CONCLUSION}

Ramadan fasting and aerobic exercise can be combined effectively to reduce body weight via fat mass and to prevent dislipideamia. However, a state of dehydration can be noticed if the climate condition during Ramadan was stressful. The state of dehydration is reflected in elevated concentrations of urea, uric acid, creatinine, and serum levels of sodium and chloride. Individuals engaging in aerobic exercise during a hot and humid month of Ramadan should drink plentiful amounts of fluid during the nighttime to compensate for the dehydration that occurs during daylight.

\section{ACKNOWLEDGMENTS}

The authors would like to thank the subjects involved for their efforts, commitment and enthusiasm throughout the study. This study was conducted with the approval of the Research Ethics Committee of the faculty of medicine of Sfax, Tunisia.

Conflict of interests: None

\section{REFERENCES}

1. Trepanowski JF, Bloomer RJ. The impact of religious fasting on human health. Nutr J 2010;9:57.

2. Azizi F. Research in islamic fasting. Ann Saudi Med 2002;22:168-91. 
3. Bahammam A. Assessment of sleep patterns, daytime sleepiness, and chronotype during Ramadan in fasting and nonfasting individuals. Saudi Med J 2004;26:616-22.

4. Finch GM, Day J EL, Welch, DA, et al. Appetite changes under free-living conditions during Ramadan fasting. Appetite 1989;31:159-70.

5. Husain R, Duncan MT, Cheah SH, et al. Effects of fasting in Ramadan on Tropical Asiatic Moslems. Br J Nutr. 1987;58:41-8.

6. Bouhlel E, Salhi Z, Bouhlel H, et al. Effect of Ramadan fasting on fuel oxidation during exercise in trained male rugby players. Diabetes Metab 2006;32:617-24.

7. Chaouachi A, Chamari K, Roky R, et al. Lipid profiles of judo athletes during Ramadan. Int J Sports Med 2008;29:282-8.

8. Ramadan J, Telahoun G, Al-Zaid NS, et al. Responses to exercise, fluid, and energy balances during Ramadan in sedentary and active males. Nutrition 1999;15:735-9.

9. Tayebi SM, Hanachi P, Niaki AG, et al. Ramadan fasting and weight-lifting training on vascular volumes and hematological profiles in young male weight-lifters. Global J health Sci 2010;2:160-6.

10. Chennaoui M, Desgorces F, Drogou C, et al. Effects of Ramadan fasting on physical performance and metabolic, hormonal, and inflammatory parameters in middle-distance runners. Appl Physiol Nutr Metab 2009;34:587-94.

11. Karli U, Guvenc A, Aslan A, et al. Influence of Ramadan fasting on anaerobic performance and recovery following short time high intensity exercise. J Sports Sci Med 2007;6:490-7.

12. Maughan RJ, Leiper JB, Bartagi Z, et al. Effect of Ramadan fasting on some biochemical and haematological parameters in Tunisian youth soccer players undertaking their usual training and competition schedule. J Sports Sci 2008;26:39-46.

13. Faye J, Fall A, Badji L, Cissé F, et al. Effet du ramadan sur le poids, la performance et la glycémie au cours d'un entraînement à la résistance. Dakar Med 2005;50:146-51.

14. Aziz AR, Wahid MF, Png W, et al. Effects of Ramadan fasting on 60 min of endurance running performance in moderately trained men. Br J Sports Med 2010;44:516-21.

15. Borg G. An introduction to Borg's RPE-scale. Ithaca, NY: Mouvement Publications.1985.

16. Durnin JVGA, Womorsley J. Body fat assessed from total density and its estimation from skinfold thickness: measurements on 481 men and women aged from 16 to 72 years. Br J Nutr 1974;32:77-97.

17. El Ati J, Beji C, Danguir J. Increased fat oxidation during Ramadan fasting in healthy women: An adaptive mechanism for body-weight maintenance. Am J Clin Nut 1995;62:302-7.

18. Bigard AX, Boussif M, Chalabi H, et al. Alterations in muscular performance and orthostatic tolerance during Ramadan. Aviat Space Environ Med 1998;69:341-6.

19. Degoutte F, Jouanel P, Bègue RJ, et al. Food restriction, performance, biochemical, psychological, and endocrine changes in Judo athletes. Int J Sports Med 2006;27:9-18.

20. Opstad K. Androgenic hormones during prolonged physical stress, sleep, and energy deficiency. J Clin Endocr Metab 1992;74: 1176-83.

21. Kakadiya J, Shah N. Renal function markers: a short review. JITPS 2010;1:270-3.

22. Banfi G. Serum creatinine concentrations in athletes: are they normal? Brazilian J Biomot 2010;4:157-64.

23. Kand'a'r R, Z`a’kova’P, Mu”a’kova V. Monitoring of antioxidant properties of uric acid in humans for a consideration measuring of levels of allantoin in plasma by liquid chromatography. Clinica Chimica Acta 2006;365:249-56.

24. Hellsten Y, Sjödin B, Richter EA, et al. Urate uptake and lowered ATP levels in human muscle after high-intensity intermittent exercise. Am J Physiol 1998;27:600-6.

25. Finaud J, Degoutte F, Scislowski, et al. Competition and Food Restriction Effects on oxidative stress in Judo. Int J Sports Med 2006;27:834-41.

26. Oppliger RA, Bartok C. Hydration Testing of Athletes. Sports Med 2002;32:959-71.

27. Anagnostopoulos T, Edelman A, Planelles G, et al. Transport du chlore dans le tube proximal Ses effets sur l'absorption hydroélectrolytique. J Physiol (Paris) 1984;79:132-8.

28. Gordon DJ, Rifkind BM. High-density lipoprotein--the clinical implications of recent studies. New Engl J Med 1989;321:13116. 